\title{
Diversity of the gut microbiota and eczema in early life
} Erick Forno 1,3,4, Andrew B Onderdonk1,3,5, John McCracken ${ }^{6}$, Augusto A Litonjua ${ }^{1,2,3}$, Daniel Laskey ${ }^{1}$, Mary L Delaney ${ }^{1,5}$, Andrea M DuBois 1,5 , Diane R Gold ${ }^{1,3}$, Louise M Ryan ${ }^{6}$, Scott T Weiss ${ }^{1,3}$ and Juan C Celedón*1,2,3 \author{
of Public Health, Boston, MA, USA \\ Email: Erick Forno - erick.forno@childrens.harvard.edu; Andrew B Onderdonk - aonderdonk@partners.org; \\ John McCracken - jmccrack@hsph.harvard.edu; Augusto A Litonjua - augusto.litonjua@channing.harvard.edu; \\ Daniel Laskey - redhl@channing.harvard.edu; Mary L Delaney - mdelaney@rics.bwh.harvard.edu; \\ Andrea M DuBois - adubois@rics.bwh.harvard.edu; Diane R Gold - diane.gold@channing.harvard.edu; \\ Louise M Ryan - lryan@hsph.harvard.edu; Scott T Weiss - scott.weiss@channing.harvard.edu; \\ Juan C Celedón* - juan.celedon@channing.harvard.edu \\ * Corresponding author
}

Address: ${ }^{1}$ Channing Laboratory Boston, MA, USA, ${ }^{2}$ Division of Pulmonary/Critical Care Medicine, Dept. of Medicine, Brigham and Women's Hospital, Boston, MA, USA, ${ }^{3}$ Harvard Medical School, Boston, MA, USA, ${ }^{4}$ Division of Pediatric Pulmonology, Dept. of Pediatrics, Children's Hospital, Boston, MA, USA, ${ }^{5}$ Dept. of Pathology, Brigham and Women's Hospital, Boston, MA, USA and ${ }^{6}$ Dept. of Biostatistics, Harvard School

Published: 22 September 2008

Clinical and Molecular Allergy 2008, 6:I I doi: |0.1 |86//476-796I-6-II
Received: 31 July 2008

Accepted: 22 September 2008

This article is available from: http://www.clinicalmolecularallergy.com/content/6/I/II

(C) 2008 Forno et al; licensee BioMed Central Ltd.

This is an Open Access article distributed under the terms of the Creative Commons Attribution License (http://creativecommons.org/licenses/by/2.0), which permits unrestricted use, distribution, and reproduction in any medium, provided the original work is properly cited.

\begin{abstract}
Background: A modest number of prospective studies of the composition of the intestinal microbiota and eczema in early life have yielded conflicting results.

Objective: To examine the relationship between the bacterial diversity of the gut and the development of eczema in early life by methods other than stool culture.

Methods: Fecal samples were collected from $2 I$ infants at $I$ and 4 months of life. Nine infants were diagnosed with eczema by the age of 6 months (cases) and 12 infants were not (controls). After conducting denaturating gradient gel electrophoresis (DGGE) of stool samples, we compared the microbial diversity of cases and controls using the number of electrophoretic bands and the Shannon index of diversity $\left(H^{\prime}\right)$ as indicators.

Results: Control subjects had significantly greater fecal microbial diversity than children with eczema at ages I (mean $H^{\prime}$ for controls $=0.75$ vs. 0.53 for cases, $P=0.0 \mathrm{I}$ ) and 4 months (mean $H^{\prime}$ for controls $=0.92$ vs. 0.59 for cases, $P=0.02$ ). The increase in diversity from I to 4 months of age was significant in controls $(P=0.04)$ but not in children who developed eczema by 6 months of age $(P=0.32)$.

Conclusion: Our findings suggest that reduced microbial diversity is associated with the development of eczema in early life.
\end{abstract}




\section{Background}

Eczema is often the first manifestation of atopy in infants who will develop asthma or allergic rhinitis later in childhood [1]. The prevalence of atopic diseases such as eczema has been on the rise for several decades, particularly in industrialized nations $[2,3]$. Potential explanations for the increased prevalence of eczema and other atopic diseases include reduced exposure to microbial agents (the "hygiene hypothesis"[4]) and/or changes in the gut microbiota in early life [5].

Few prospective studies have examined the relation between the composition of the gut microbiota in early life and atopy [6-9]. A study of 324 European infants followed from birth to age 18 months found that neither time to gut colonization with 11 bacterial groups nor ratio of strict anaerobic to facultative anaerobic bacteria in cultures from neonatal stool samples was associated with eczema or food allergy [7]. In contrast, a study of 957 Dutch infants showed that the presence of $C$. difficile in stool samples at age 1 month (assessed by quantitative real-time PCR) was associated with increased risks of eczema, recurrent wheeze, and allergic sensitization at age 2 years [8]. In that study, early colonization with E. coli was associated with eczema by parental report but not with objectively diagnosed eczema. The conflicting results of these studies may be due to differences in statistical power and/or limited ability to adequately culture the complex gut microbiota [10].

Novel methods such as analysis of bacterial 16S ribosomal DNA [rDNA] (using universal primers or denaturating techniques) $[11,12]$ are much more sensitive for detecting certain bacterial species in the mouth or gut than traditional cultures. Using temporal temperature gradient gel electrophoresis (TTGE), Li and colleagues found a significant difference in the diversity of the oral microbiota of children with and without severe dental caries [13]. Using a similar approach, Wang and colleagues recently reported that reduced diversity of the gut microbiota at age 1 week is associated with eczema in the first 18 months of life [9].

We performed denatured gradient gel electrophoresis (DGGE) analysis of bacterial 16S rDNA genotypes on stool samples to assess whether the microbial diversity of the gut microbiota at ages 1 and 4 months is associated with the development of eczema in early life. We report that reduced microbial diversity of the neonatal gut microbiota in the first 4 months of life is associated with an increased risk of eczema at age 6 months.

\section{Methods \\ Study cohort}

Pregnant women were recruited between July 2003 and November 2005 from three outpatient facilities affiliated with Brigham and Women's Hospital in Boston at their 24 -week prenatal visit, as previously described [14]. Inclusion criteria were maternal age between 18 years and 44 years; plans to deliver at Brigham and Women's Hospital; and maternal ability to speak English or Spanish. Informed consent was obtained from participating mothers. Of the 37 participating neonates, nine had been diagnosed with eczema by a physician before age 6 months and were included as cases for this analysis. Twelve healthy children (no diagnosis of eczema) were then matched to the cases on gender and included as control subjects for this study. The study was approved by the Institutional Review Board of Brigham and Women's Hospital.

A questionnaire was administered to each participating woman between her 24-week prenatal visit and delivery to obtain information on demographics, general health, and history of allergic diseases and/or symptoms for each of the child's parents.

Information on labor and delivery was obtained from review of medical records. When the child was 2 and 6 months of age, a telephone questionnaire (modified from the American Thoracic Society-Division of Lung Diseases questionnaire [15]) was administered by trained research assistants to the child's primary caretaker.

\section{Stool collection and denatured gradient gel electrophoresis (DGGE) analysis of bacterial I 6S rDNA in stool samples}

A stool sample was collected from participating neonates at ages 1 and 4 months. More than a gram of stool was collected into a sterile specimen container and frozen for transport to the laboratory. Approximately 0.05 gram of stool specimen was placed into a $1.5 \mathrm{ml}$ sterile tube. Following the fecal DNA purification protocol supplied by the manufacturer, DNA was extracted using the ExtractMaster Fecal DNA extraction kit (EPICENTRE Biotechnologics, Madison, WI). The V2-V3 region of the 16S rDNA gene of bacteria in the fecal samples was amplified using the primers described by Tannock et al [16]. PCR was performed using a Biorad thermal cycler and $0.2 \mathrm{ml}$ tubes. The reaction mixture $(50 \mu \mathrm{L})$ contains Platinum PCR SuperMix High Fidelity (Invitrogen, Carlsbad CA), 1 unit of Platinum Taq DNA Polymerase High Fidelity (Invitrogen), $20 \mathrm{pmol}$ of each primer and $4 \mu \mathrm{l}$ of fecal DNA. Amplification was $94^{\circ} \mathrm{C}$ for 3 minutes, 30 cycles of $94^{\circ} \mathrm{C}$ for $30 \mathrm{~s}, 56^{\circ} \mathrm{C}$ for $30 \mathrm{~s}, 68^{\circ} \mathrm{C}$ for $60 \mathrm{~s}$ and 7 minutes at $68^{\circ} \mathrm{C}$ at the end of the cycles. DGGE was performed using the DCode universal mutation detection system (Bio-Rad 
Laboratories, Hercules CA) in gels that were $16 \mathrm{~cm} \times 16$ $\mathrm{cm}$ by $1 \mathrm{~mm} ; 6 \%$ polyaccrylamide gels were prepared and electrophoresed with $1 \times$ tris-acetate EDTA (TAE) buffer prepared from $50 \times$ TAE buffer. The denaturing gradient was formed by using two 6\% polyacrylamide stock solutions containing a $20-55 \%$ urea/formamide gradient that increases in the direction of electrophoresis. A $100 \%$ denaturing solution containing $40 \%$ formamide and 7.0 $\mathrm{M}$ urea was used. Electrophoresis was performed at $130 \mathrm{~V}$ and $60^{\circ} \mathrm{C}$ for approximately 4 hours. The electrophoresis was stopped when a xylene cyanol dye marker reached the bottom of the gel. Gels were stained with ethidium bromide solution $(5 \mu \mathrm{g} / \mathrm{mL})$ for 20 minutes, washed with deionized water and viewed using a Gel Doc UV transillumination system (Bio-Rad).

\section{Statistical analysis}

The number of DGGE bands was used as an indicator of fecal bacterial diversity for each participating child, both at 1 and at 4 months of age. Densitometric curves were obtained for all the bands in each sample, and the relative intensity of each band in the sample $\left(p_{i}\right)$ was computed. Shannon diversity indices $\left(H^{\prime}\right)$ were then calculated for each patient at 1 and 4 months of age, using the formula $H^{\prime}=-\Sigma p_{i}^{*} \ln \left(p_{i}\right)[17]$
Univariate analysis for baseline characteristics was performed using Mann-Whitney rank-sum tests. The differences in bacterial diversity between cases and controls at each point in time ( 1 and 4 months of age) were tested by Mann-Whitney rank-sum tests and by logistic regression modeling; non-parametric analysis was repeated after stratification by mode of delivery. We explored the behavior of bacterial diversity over time using mixed effects linear modeling in order to account for correlations between repeated measures on the same subjects [18]. An interaction term between time and eczema status was included to assess the differential effect of time in the two groups. All statistical analysis was performed using SAS v9.1 (SAS Institute Inc., Cary, NC).

\section{Results}

Table 1 shows the main characteristics of participating children. Approximately half of the children were girls (by matching design) who were born by vaginal delivery and who were breastfed. There were no significant differences in breastfeeding, mode of delivery, birthweight, 5-minute APGAR score, day care attendance, or use of antibiotics between children who did and did not develop eczema by age 6 months.

The results of the analysis of the mean number of DGGE bands (representing bacterial 16S rDNA profiles, see Fig-

Table I: Characteristics of participating children

\begin{tabular}{|c|c|c|c|c|}
\hline & Total n (\%) & Eczema' n (\%) & Controls n (\%) & P-value ${ }^{2}$ \\
\hline \multicolumn{5}{|l|}{ Gender: } \\
\hline -Male & II (52.4) & $4(44.4)$ & $7(58.3)$ & 0.67 \\
\hline Mode of delivery: & & & & 0.67 \\
\hline -Vaginal & $10(47.6)$ & $5(55.6)$ & $5(4 \mid .7)$ & \\
\hline -Cesarean & II (52.4) & $4(44.4)$ & $7(58.3)$ & \\
\hline Maternal history of atopy & $12(57.1)$ & $7(77.8)$ & $5(4 I .7)$ & 0.18 \\
\hline Term delivery ${ }^{3}$ & $17(81.0)$ & $7(77.8)$ & $10(83.3)$ & 1.00 \\
\hline Birthweight (g), mean (SD) & $3319(688)$ & $3192(395)$ & $34 I 5(85 I)$ & 0.24 \\
\hline 5-minute APGAR, median & 9 & 9 & 9 & 0.50 \\
\hline Breastfed & II (52.4) & $6(66.7)$ & $5(4 I .7)$ & 0.39 \\
\hline Daycare attendance & $5(23.8)$ & $\mathrm{I}(\mathrm{II} . \mathrm{I})$ & $4(33.3)$ & 0.34 \\
\hline Use of antibiotics ${ }^{4}$ & $3(18.8)$ & I (16.7) & $2(20.0)$ & 1.00 \\
\hline \multicolumn{5}{|c|}{ Measures of bacterial diversity: } \\
\hline \multicolumn{5}{|c|}{ DGGE bands ${ }^{5}$, mean $(95 \% \mathrm{Cl})$ : } \\
\hline-1 month of age & $4.4(3.6-5.1)$ & $3.8(2.6-4.9)$ & $4.8(3.8-5.9)$ & 0.10 \\
\hline-4 months of age & $5.3(3.8-6.7)$ & $3.9(2.3-5.4)$ & $6.5(4.2-8.8)$ & 0.06 \\
\hline \multicolumn{5}{|c|}{ Shannon index 6 , mean $(95 \% \mathrm{Cl})$ : } \\
\hline-1 month of age & $0.66(0.55-0.76)$ & $0.53(0.38-0.67)$ & $0.75(0.63-0.88)$ & 0.01 \\
\hline-4 months of age & $0.77(0.62-0.91)$ & $0.59(0.38-0.81)$ & $0.92(0.76-1.08)$ & 0.02 \\
\hline
\end{tabular}


ure 1) and the Shannon diversity indices in participating children are included in Table 1 and illustrated in Figure 2. There was a trend for a higher mean number of bands in controls than in children with eczema at 1 month of life, with a more pronounced difference at 4 months. Similarly, controls had significantly higher indices of diversity $\left(H^{\prime}\right)$ than cases, both at 1 and at 4 months. The observed differences in the index of diversity at ages 1 and 4 months remained statistically significant after adjustment for mode of delivery and maternal history of atopy (data not shown).

We then examined the relation between increasing bacterial diversity and eczema in bivariate analyses using logistic regression (Table 2 ). At age 1 month, an increment in the Shannon diversity index from the mean value for cases (0.53) to the mean value for controls (0.75) was associated with a $70 \%$ reduction in the odds of eczema by age 6 months. There was a similar yet nonstatistically significant trend for an inverse association between the number of electrophoretic bands and eczema. At age 4 months, an increment in the number of bands from the mean value for cases (3.9) to the mean value for controls (6.5) was associated with a $75 \%$ reduction in the odds of eczema by age 6 months. In addition, an increment in the Shannon diversity from the mean value for cases (0.59) to the mean value for controls (0.92) at age 4 months was associated with an $85 \%$ reduction in the odds of eczema. The results of analyses of microbial diversity and eczema were not appreciably changed after adjustment for relevant covariates (Table 2).

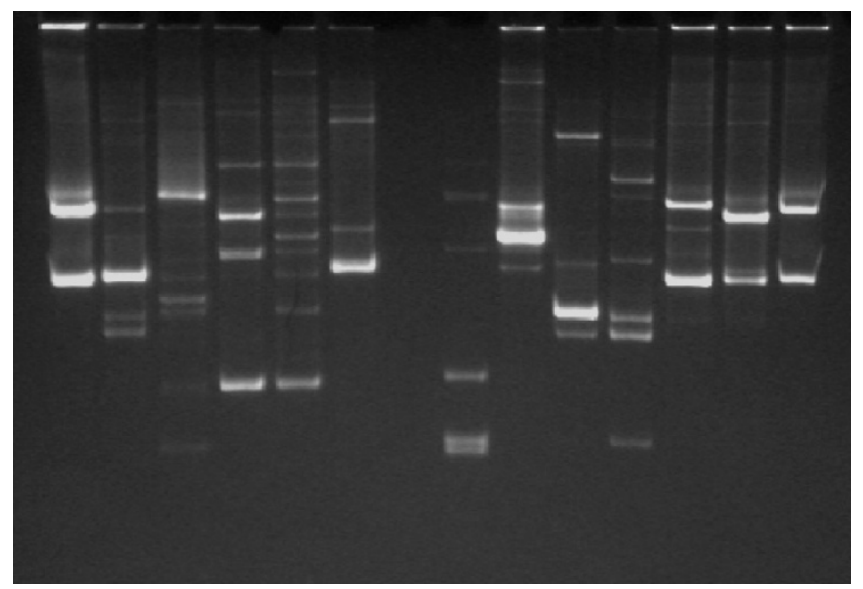

Figure I

Denaturating gradient gel electrophoresis (DGGE).

Stool samples were processed to extract I6S rDNA, the V2$\mathrm{V} 3$ region was amplified by $P C R$, and denaturating gradient gel electrophoresis (DGGE) was performed using a standard protocol. For each lane, representing a single sample, the number of bands was counted and the Shannon index of diversity $H^{\prime}$ was calculated.
Because of the known influence of mode of delivery on the neonatal gut microbiota, we repeated the analysis after stratification by mode of delivery (Table 3 and Figure 3). Among children delivered vaginally, both measures of diversity were significantly higher in controls than in cases at the age of 1 month, with a non-statistically significant difference at 4 months. Among children born by cesarean section, controls had a significantly higher Shannon index at age 4 months of age, with no significant difference at 1 month. Odds ratios were not calculated due to the small number of subjects in each subgroup.

Mixed effects linear regression modeling was used to directly evaluate the behavior of bacterial diversity over time, with an interaction term included to assess whether the effect of time differed between cases and controls. Both models are illustrated in Figure 4. For the number of bands, there was no difference between cases and controls at 1 month of age. Controls acquired an average of 1.3 bands from age 1 month to age 4 months ( $\mathrm{p}=0.09)$, whereas cases only increased by 0.1 bands $(p=0.87)$; this resulted in a significant difference by age 4 months, with controls having on average 2.6 more bands than cases $(\mathrm{p}$ $=0.04$ ). For the Shannon index model, controls had a significantly higher diversity than cases at 1 and 4 months of age, as previously described. During that period, $H^{\prime}$ increased an average of 0.11 among controls ( $p=0.04)$, whereas the increase among cases was not significant $(\mathrm{p}=$ $0.32)$.

\section{Discussion}

DGGE is a method to assess bacterial microbiota that is culture-independent and is based on electrophoresis of denaturated bacterial $16 \mathrm{~S}$ rDNA genotypes. Using the number of electrophoretic bands and the Shannon index as markers of gut microbial diversity, we found that a reduced fecal bacterial diversity is associated with an increased risk of physician-diagnosed eczema in early life. These findings extend those of a recent report by Wang and colleagues of an inverse association between bacterial diversity of the gut microbiota at 1 week of age and eczema diagnosed by the age of 18 months in European infants, using terminal restriction fragment length polymorphism (T-RFLP) and temporal temperature gradient electrophoresis (TTGE)[9]. Our results suggest that differences in microbial diversity of the gut between children who will and will not develop eczema in infancy persist up to age 4 months and in fact increase during the first months of life.

An inverse association between family size and hay fever led to the hypothesis that reduced microbial exposure in early life increases the risk of developing allergic diseases (the "hygiene hypothesis") [4,19]. Several potential mechanisms have been proposed. $\mathrm{T}_{\mathrm{H}} 2$ cells promote aller- 

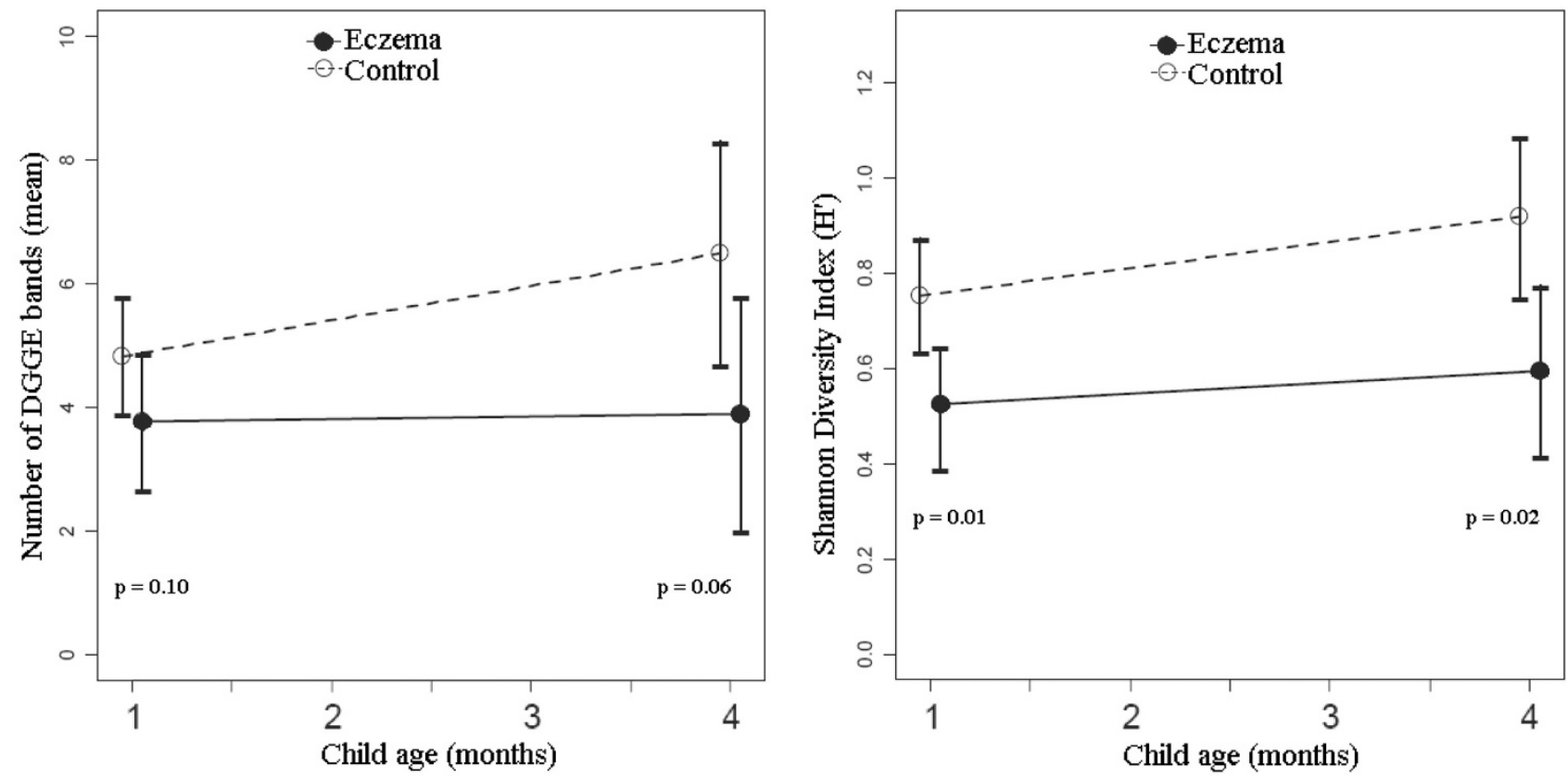

Figure 2

Number of bands and Shannon diversity index in all subjects. Controls had a higher number of bands at age 4 months $(p=0.06)$, and a higher Shannon index both at $I(p=0.01)$ and 4 months of age $(p=0.02)$.

gen-specific responses via cytokines that increase production of IgE, eosinophilia, and mast cell proliferation $[20,21]$. In neonates, the immune system is skewed towards a $\mathrm{T}_{\mathrm{H}} 2$ profile [22], and it has been postulated that

Table 2: Fecal microbial diversity at ages I and 4 months, and eczema' at age 6 months.

\begin{tabular}{cccc}
\hline & & \multicolumn{2}{c}{ Odds ratio $^{2}(95 \% \mathrm{Cl})$} \\
\cline { 3 - 4 } & Age & Unadjusted & Adjusted $^{3}$ \\
\hline DGGE bands $^{4}$ & I month & $0.61(0.28-1.13)$ & $0.52(0.19-1.08)$ \\
& 4 months & $0.25(0.04-0.87)$ & $0.19(0.01-0.87)$ \\
& & & \\
Shannon index & & & \\
& I month & $0.30(0.08-0.80)$ & $0.23(0.04-0.7 I)$ \\
& 4 months & $0.15(0.01-0.66)$ & $0.08(0.01-0.58)$
\end{tabular}

'Defined as maternal report of physician-diagnosed eczema at or before 6 months of age

2Odds ratio of having eczema if fecal microbial diversity (number of bands or Shannon index) increases from the mean value for cases to the mean value for controls (e.g. from 3.8 to 4.8 bands at I month, etc).

${ }^{3}$ Adjusted for mode of delivery and maternal history of atopy. Adjusted odds ratios were not significantly different than unadjusted ones.

${ }^{4}$ Number of denaturating gradient gel electrophoresis (DGGE) bands in each sample

${ }^{5}$ Shannon diversity index $\left(H^{\prime}\right)$ calculated using the relative intensity of all bands within each sample a decreased microbial exposure increases the risk of atopy because of an insufficient shift towards a more balanced $\mathrm{T}_{\mathrm{H}} 1 / \mathrm{T}_{\mathrm{H}} 2$ response ("missing immune deviation") [20,23]. $\mathrm{T}_{\text {REG }}$ cells, a newly characterized group of immune-modulatory $\mathrm{T}$ cells, suppress $\mathrm{T}_{\mathrm{H}} 1$ and $\mathrm{T}_{\mathrm{H}} 2$ activity by several mechanisms [24-26]. Early antigen exposure may influence $\mathrm{T}_{\mathrm{REG}}$ activity [27].

To date, no specific microbe or microbial product responsible for these observations has been confidently identified. The gut is the most important source of postnatal microbial stimulation of the immune system [28]. In experimental models, neonate mice with sterile gastrointestinal tracts do not develop a normal $\mathrm{T}_{\mathrm{H}} 1 / \mathrm{T}_{\mathrm{H}} 2$ balance [29]; reintroduction of bacteria normalizes such balance $[30,31]$. Exposure of murine $\mathrm{T}_{\mathrm{REG}}$ cells to lipopolysaccharide stimulates their activity by expression of Toll-like receptors [32]. Murosaki [33] and Shida [34] have demonstrated that certain species of Lactobacillus decrease in vivo production of IgE in mice. Recently, Forsythe and colleagues reported that oral $L$. reuteri decreased eosinophilia and allergen-induced airway responsiveness in a murine model [35].

Human studies of the gut microbiota and allergies have yielded conflicting results. Adlerberth et al. found no association between any of 11 fecal bacterial groups and atopy 

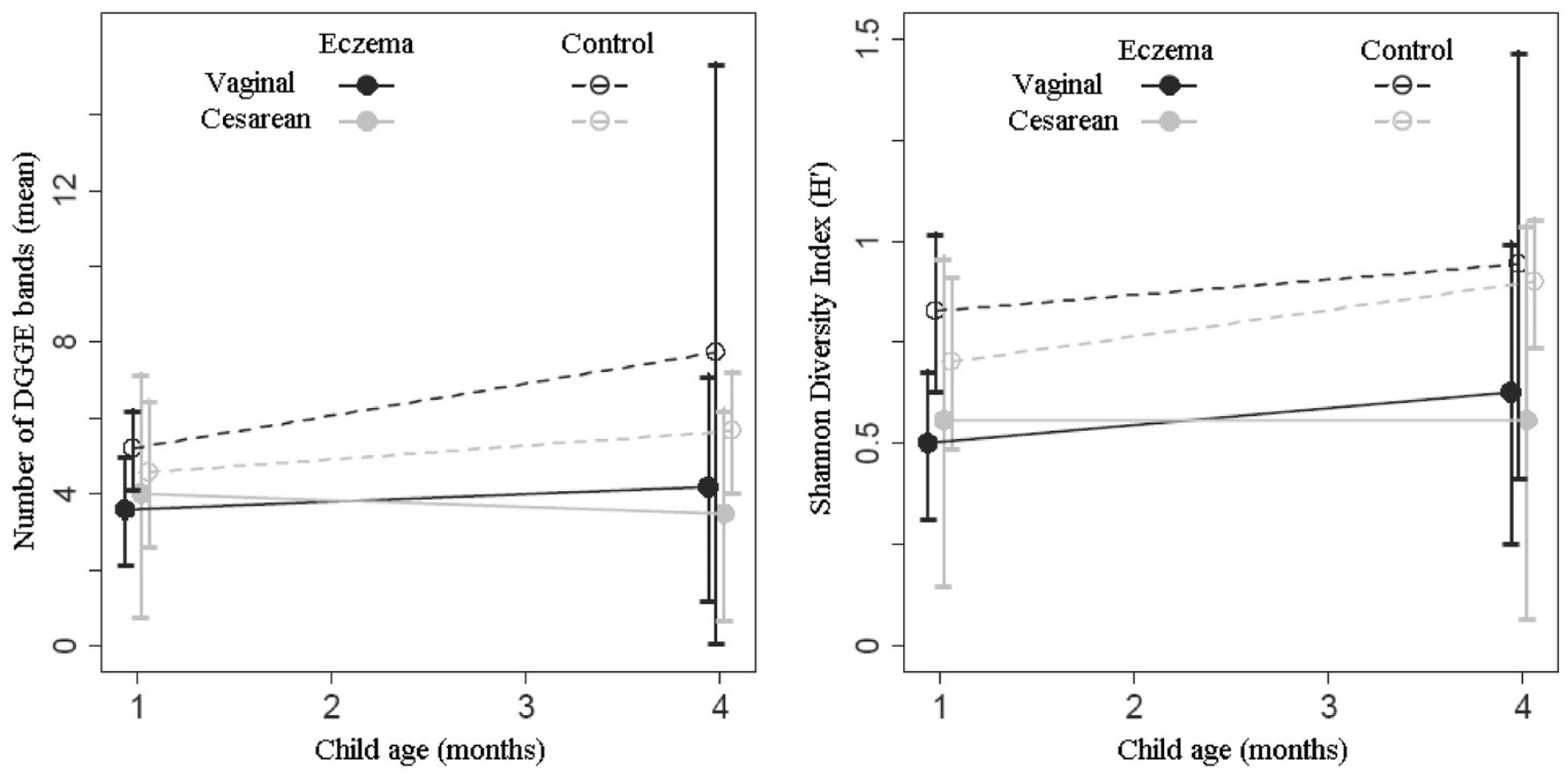

Figure 3

Number of bands and Shannon diversity index by mode of delivery: Controls delivered vaginally had a higher Shannon index than cases at I month $(p=0.04)$ but not at 4 months; index for controls delivered by $C$-section was similar to cases at I month, but higher at 4 months $(p=0.04)$.

in a cohort of European children [7]. On the other hand, Penders and colleagues found an association between $C$. difficile in stool samples at age 1 month and several markers of atopy in 957 Dutch infants [8]. Small clinical trials have found that oral supplementation of probiotics containing different species of lactobacilli and bifidobacteria result in reduced severity of eczema [36-38]. Both murine models and human studies have failed to isolate specific bacteria associated with atopy in a consistent manner. Rather than attempting to reduce the cause of these abnormalities in the immune system to the level of a specific causative organism, a systems biology approach would suggest the key factor is the alteration of the gut microbiota as a whole.

Table 3: Fecal microbial diversity at ages I and 4 months, and eczema' at age 6 months, stratified by mode of delivery

\begin{tabular}{|c|c|c|c|c|c|c|c|}
\hline & \multirow[b]{3}{*}{ Age } & \multicolumn{3}{|c|}{ Vaginal Delivery² } & \multicolumn{3}{|c|}{ Cesarean Section ${ }^{2}$} \\
\hline & & \multicolumn{2}{|c|}{ Means } & \multirow[b]{2}{*}{ p-value ${ }^{3}$} & \multicolumn{2}{|c|}{ Means } & \multirow[b]{2}{*}{ P-value ${ }^{3}$} \\
\hline & & Eczema & Controls & & Eczema & Controls & \\
\hline \multirow[t]{2}{*}{ DGGE bands ${ }^{4}$} & I month & 3.60 & 5.20 & 0.05 & 4.00 & 4.57 & 0.75 \\
\hline & 4 months & 4.20 & 7.75 & 0.26 & 3.50 & 5.67 & 0.12 \\
\hline \multicolumn{8}{|l|}{ Shannon index ${ }^{5}$} \\
\hline & I month & 0.50 & 0.83 & 0.04 & 0.56 & 0.70 & 0.16 \\
\hline & 4 months & 0.63 & 0.94 & 0.18 & 0.56 & 0.90 & 0.04 \\
\hline
\end{tabular}

IDefined as parental report of physician-diagnosed eczema at or before 6 months of age

2There was no difference in microbial diversity when comparing delivery modes regardless of eczema status $(p>0.90)$

3 Mann-Whitney U-test p-value

${ }^{4}$ Number of denaturating gradient gel electrophoresis (DGGE) bands in each sample

${ }^{5}$ Shannon diversity index $\left(H^{\prime}\right)$ calculated using the relative intensity of all bands within each sample 

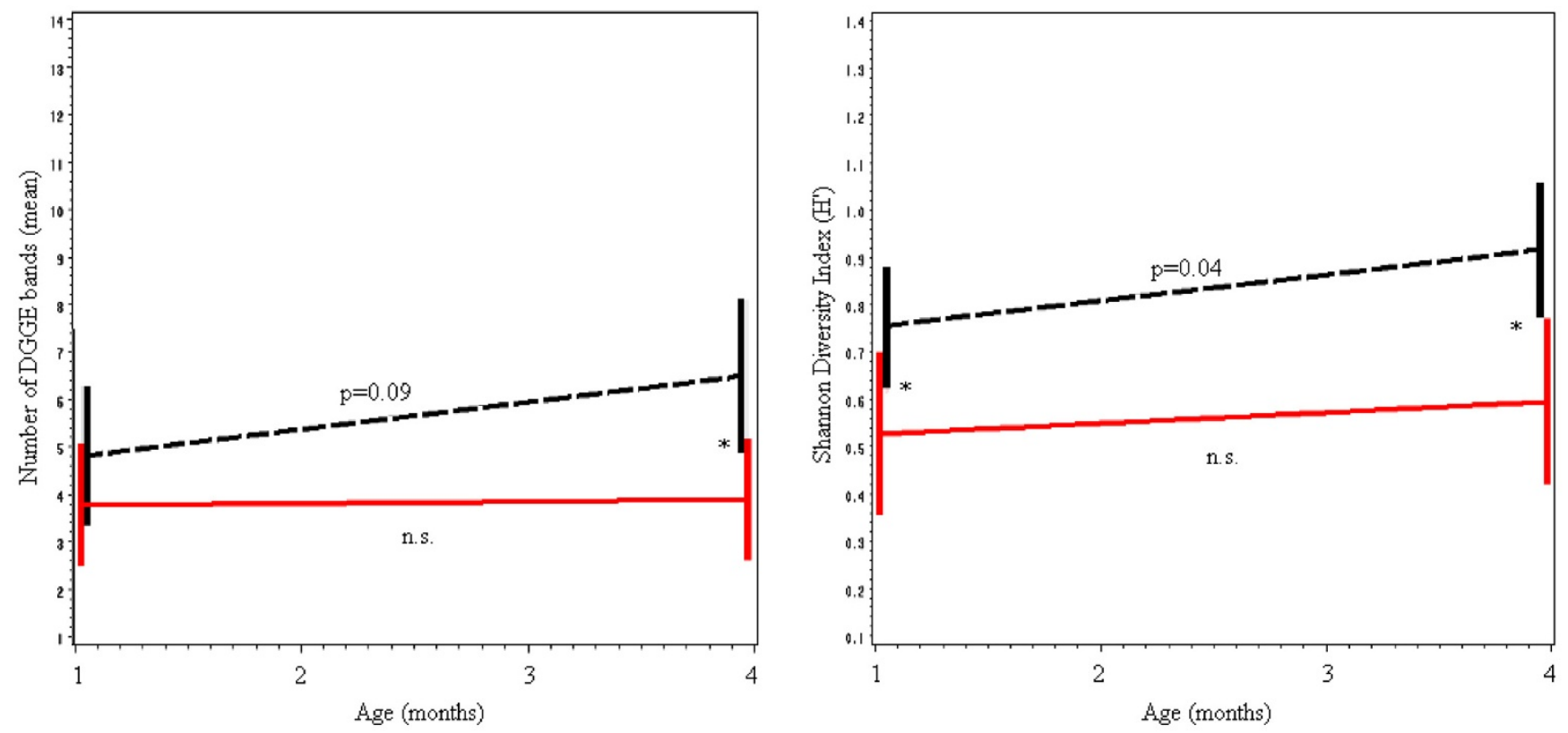

Figure 4

Predictions from mixed effects linear regression models. (Note: cases in red; controls in black). Number of bands: The increase in the number of bands tends to be more substantial in controls $(p=0.09)$ than in cases $(p=0.87)$; by age 4 months, controls have on average 2.6 bands more than cases. Shannon index: $H^{\prime}$ increases significantly in controls $(p=0.04)$ but not in cases ( $p=0.32$ ); at I month of age the index for controls is 0.22 higher, and at 4 months it is 0.33 higher. $\left({ }^{*} p<0.05\right.$; see Table I).

An alternate plausible explanation for the observed association between an anomalous gut microbiota and eczema is that the abnormalities in the immune system that lead to the disease (e.g., failure to develop a balanced $\mathrm{T}_{\mathrm{H}} 1 / \mathrm{T}_{\mathrm{H}} 2$ response by age 1 year, lack of a normal $\mathrm{T}_{\mathrm{REG}}$ activity, etc.) prevent the acquisition or preservation of a "normally diverse" gut microbiota. The decreased bacterial diversity and the development of eczema would be parallel consequences of the same underlying mechanisms. However, a causal relationship is supported both by experimental data demonstrating the restitution of normal immune function and decreased inflammation in mice after reintroduction of bacteria [30-35], and by human studies demonstrating prevention or improvement of atopic dermatitis in infants after probiotic administration [36-39].

Of interest, a reduced microbial diversity has been implicated in various diseases. Li and colleagues found that the microbial diversity of the oral cavity was significantly reduced in children with severe early-childhood caries [40] when compared to controls. A potential explanation for this finding is that certain groups of bacteria supplant or dominate the plaque flora in individuals with caries, whereas caries-free individuals have a more diverse flora with no subgroup predominance. Abnormalities in quan- tity or composition of the fecal microbiota have been linked to diseases such as ulcerative colitis [41], Crohn's disease [42,43], and celiac disease [44,45].

The association between atopic eczema and subsequent development of asthma in children is well recognized [46]. A recent study by Burgess et al showed that a history of childhood eczema is also associated with new-onset of asthma later in life and with asthma persisting into middle age [47]. Being able to identify infants at risk and prevent the development of eczema would not only lessen the burden of the disease itself, but could also help identify children at risk for and perhaps help prevent asthma in those infants later in childhood and into adulthood.

Non-culture dependent methods such as DGGE have better sensitivity to detect certain bacterial species than stool cultures, which may provide incomplete data because of inability to detect non-culturable bacteria. These new methods provide a more accurate view of the bacterial community and allow for the study of the whole system, rather than focusing on specific species. Although it would have been ideal to perform full genotyping and sequencing of bacterial DNA, we were limited by our sample size. Similarly, potential differences in the relation between microbial diversity and eczema by mode of deliv- 
ery must be interpreted with caution because of the small sample size of our study. History of antibiotic usage by the infants was not associated with the diagnosis of eczema; although information was missing on 2 subjects ( 1 control and 1 case), sensitivity analysis for the missing data showed no change in the results.

\section{Conclusion}

We found a significant inverse association between fecal bacterial diversity and eczema in early life. In addition, we found a significant increment in fecal bacterial diversity from ages 1 to 4 months in healthy children, but not in children who developed eczema by age 6 months. Further research is needed to investigate these findings, including larger sample sizes to elucidate the effect of time and other factors known to be associated with bacterial diversity and/or atopy, DGGE standardization and genotyping to identify groups of bacteria and patterns associated with the development of eczema, and long-term follow-up to provide information regarding development of other atopic diseases such as asthma.

\section{Competing interests}

Please see additional file 1 which contains the disclosure for Dr. Scott T. Weiss. All other authors declare that they have no competing interests.

\section{Authors' contributions}

EF participated in the data analysis and interpretation, and the preparation of the manuscript. JCC, AAL, DRG, and STW participated in the study design and data interpretation. JCC also participated in the manuscript preparation. DL participated in the coordination of the study and the collection of data. ABO, MLD and AMD processed the samples and performed the PCR and DGGE. JMcC and LMR participated in the data analysis. All authors read and approved the final manuscript.

\section{Additional material}

\section{Additional file 1 \\ Competing interests disclosure. Disclosure of competing interests for Dr. Scott T. Weiss \\ Click here for file \\ [http://www.biomedcentral.com/content/supplementary/1476- 7961-6-11-S1.doc]}

\section{Acknowledgements}

We would like to thank the families in the study for their enthusiastic participation.

This study was supported by a grant from the Harvard NIEHS (National Institute of Environmental Health Sciences) Center.

\section{References}

I. Beck LA, Leung DYM: Allergen sensitization through the skin induces systemic allergic responses. Journal of Allergy and Clinical Immunology 2000, 106:258-263.

2. Asher MI, Montefort S, Bjorksten B, Lai CK, Strachan DP, Weiland $\mathrm{SK}$, Williams $\mathrm{H}$ : Worldwide time trends in the prevalence of symptoms of asthma, allergic rhinoconjunctivitis, and eczema in childhood: ISAAC Phases One and Three repeat multicountry cross-sectional surveys. The Lancet 2007, 368:733-743.

3. Williams $\mathrm{H}$, Stewart A, von Mutius E, Cookson W, Anderson HR: Is eczema really on the increase worldwide. Journal of Allergy and Clinical Immunology 2008, I 2 I (4):947-54.

4. Strachan DP: Hay fever, hygiene, and household size. British Medical Journal 1989, 299: I 259-1260.

5. Martricardi PM, Ronchetti RB: Are infections protecting from atopy? Curr Opin Allergy Clin Immunol 200I, I (5):4I 3-4I 9.

6. Kalliomaki M, Kirjavainen P, Eerola E, Kero P, Salminen S, Isolauri E: Distinct patterns of neonatal gut microflora in infants in whom atopy was and was not developing. J Allergy Clin Immunol 2001, 107:129-134.

7. Adlerberth I, Strachan DP, Matricardi PM, Ahrne S, Orfei L, Aberg N, Perkin MR, Tripodi S, Hesselmar B, Saalman R, Coates AR, Bonanno $\mathrm{CL}$, Panetta $\mathrm{V}$, Wold $\mathrm{AE}$ : Gut microbiota and development of atopic eczema in 3 European birth cohorts. Journal of Allergy and Clinical Immunology 2007, I 20:343-350.

8. Penders J, Thijs C, Brandt PA van den, Kummeling I, Snijders B, Stelma F, Adams H, van Ree R, Stobberingh EE: Gut microbiota composition and development of atopic manifestations in infancy: the KOALA Birth Cohort Study. Gut 2007, 56:66 I-667.

9. Wang M, Karlsson C, Olsson C, Adlerberth I, Wold AE, Strachan DP, Martricardi PM, Aberg N, Perkin MR, Tripodi S, Coates AR, Hesselmar B, Saalman R, Molin G, Ahrné S: Reduced diversity in the early fecal microbiota of infants with atopic eczema. Journal of Allergy and Clinical Immunology 2007, I 2 I: I29-I34.

10. Eckburg PB, Bik EM, Bernstein CN, Purdom E, Dethlefsen L, Sargent $M$, Gill SR, Nelson KE, Relman DA: Diversity of the Human Intestinal Microbial Flora. Science 2005, 308:1635-1638.

II. Fujimoto C, Maeda H, Kokeguchi S, Takashiba S, Nishimura F, Arai H, Fukui K, Murayama Y: Application of denaturing gradient gel electrophoresis (DGGE) to the analysis of microbial communities of subgingival plaque. Journal of Periodontal Research 2003, 38:440-445.

12. Schabereiter-Gurtner C, Maca S, Rolleke S, Nigl K, Lukas J, Hirschl A Lubitz W, Barisani-Asenbauer T: I 6S rDNA-Based Identification of Bacteria from Conjunctival Swabs by PCR and DGGE Fingerprinting. Invest Ophthalmol Vis Sci 200 I, 42: I I64-I I 7 I.

13. Li Y, Ge Y, Saxena D, Caufield PW: Genetic Profiling of the Oral Microbiota Associated with Severe Early-Childhood Caries. J Clin Microbiol 2007, 45:8I-87.

14. Ly NP, Ruiz-Perez B, Onderdonk AB, Tzianabos AO, Litonjua AA, Liang C, Laskey D, Delaney ML, Dubois AM, Levy H, Gold DR, Ryan LM, Weiss ST, Celedón JC: Mode of delivery and cord blood cytokines: a birth cohort study. Clin Mol Allergy 2006, 4: I3.

15. Ferris B: Epidemiology Standardization Project (American Thoracic Society). Am Rev Respir Dis 1978, I I 8: I-I 20.

16. Tannock GW, Munro K, Harmsen HJM, Welling GW, Smart J, Gopal PK: Analysis of the Fecal Microflora of Human Subjects Consuming a Probiotic Product Containing Lactobacillus rhamnosus DR20. Appl Environ Microbiol 2000, 66:2578-2588.

17. Magurran A: Measuring biological diversity. Blackwell Publishing 2003.

18. Fitzmaurice G, Laird N, Ware J: Linear Mixed Effects Model. In Applied Longitudinal Analysis. Probability and Statistics Hoboken, NJ: Wiley-Interscience; 2004:187-233.

19. Strachan DP: Family size, infection and atopy: the first decade of the "hygiene hypothesis". Thorax 2000, 55(SuppI I):S2-I0.

20. Romagnani S: The increased prevalence of allergy and the hygiene hypothesis: missing immune deviation, reduced immune suppression, or both? Immunology 2004, I I 2:352-363.

21. Wahl SM, Vazquez N, Chen W: Regulatory T cells and transcription factors: gatekeepers in allergic inflammation. Curr Opin Immunol 2004, I 6:768-774.

22. Prescott SL, Macaubas C, Holt BJ, Smallacombe TB, Loh R, Sly PD, Holt PG: Transplacental priming of the human immune system to environmental allergens: universal skewing of initial 
T cell responses toward the Th2 cytokine profile. J Immunol 1998, 160:4730-4737.

23. Romagnani S: Immunologic influences on allergy and the $\mathrm{THI} /$ TH2 balance. J Allergy Clin Immunol 2004, I I 3:395-400.

24. Cottrez F, Hurst SD, Coffman RL, Groux H: T regulatory cells I inhibit a Th2-specific response in vivo. J Immunol 2000, 165:4848-4853.

25. Akbari O, Freeman GJ, Meyer EH, Greenfield EA, Chang TT, Sharpe $\mathrm{AH}$, Berry G, DeKruyff RH, Umetsu DT: Antigen-specific regulatory $T$ cells develop via the ICOS-ICOS-ligand pathway and inhibit allergen-induced airway hyperreactivity. Nat Med 2002, 8: 1024-1032.

26. Zuany-Amorim C, Sawicka E, Manlius C, Le Moine A, Brunet LR, Kemeny DM, Bowen G, Rook G, Walker C: Suppression of airway eosinophilia by killed Mycobacterium vaccae-induced allergen-specific regulatory T-cells. Nat Med 2002, 8:625-629.

27. Ostroukhova M, Seguin-Devaux C, Oriss TB, Dixon-McCarthy B, Yang L, Ameredes BT, Corcoran TE, Ray A: Tolerance induced by inhaled antigen involves CD4(+) T cells expressing membrane-bound TGF-beta and FOXP3. I Clin Invest 2004, I I 4:23-28.

28. Guarner F, Malagelada JR: Gut flora in health and disease. Lancet 2003, 361:512-519.

29. Oyama N, Sudo N, Sogawa $H$, Kubo C: Antibiotic use during infancy promotes a shift in the $T(H) I / T(H) 2$ balance toward $\mathbf{T}(\mathbf{H}) 2$-dominant immunity in mice. J Allergy Clin Immunol 200I, 107:153-159.

30. Mazmanian SK, Liu CH, Tzianabos AO, Kasper DL: An immunomodulatory molecule of symbiotic bacteria directs maturation of the host immune system. Cell 2005, I 22:107-I I8.

31. Sudo N, Yu XN, Aiba Y, Oyama N, Sonoda J, Koga Y, Kubo C: An oral introduction of intestinal bacteria prevents the development of a long-term Th2-skewed immunological memory induced by neonatal antibiotic treatment in mice. Clin Exp Allergy 2002, 32:1 I 12-1116.

32. Caramalho I, Lopes-Carvalho T, Ostler D, Zelenay S, Haury M, Demengeot J: Regulatory $\mathbf{T}$ cells selectively express toll-like receptors and are activated by lipopolysaccharide. J Exp Med 2003, I 97:403-4II.

33. Murosaki S, Yamamoto $\mathrm{Y}$, Ito $\mathrm{K}$, Inokuchi $\mathrm{T}$, Kusaka $\mathrm{H}$, Ikeda $\mathrm{H}$, Yoshikai Y: Heat-killed Lactobacillus plantarum L- 137 suppresses naturally fed antigen-specific IgE production by stimulation of IL-I 2 production in mice. J Allergy Clin Immunol 1998, 102:57-64.

34. Shida K, Takahashi R, Iwadate E, Takamizawa K, Yasui H, Sato T, Habu S, Hachimura S, Kaminogawa S: Lactobacillus casei strain Shirota suppresses serum immunoglobulin $E$ and immunoglobulin GI responses and systemic anaphylaxis in a food allergy model. Clin Exp Allergy 2002, 32:563-570.

35. Forsythe $P$, Inman MD, Bienenstock J: Oral treatment with live Lactobacillus reuteri inhibits the allergic airway response in mice. Am J Respir Crit Care Med 2007, 1 75:56I-569.

36. Isolauri E, Arvola T, Sutas Y, Moilanen E, Salminen S: Probiotics in the management of atopic eczema. Clin Exp Allergy 2000, 30:1604-1610

37. Kukkonen K, Savilahti E, Haahtela T, Juntunen-Backman K, Korpela R, Poussa T, Tuure T, Kuitunen M: Probiotics and prebiotic galactooligosaccharides in the prevention of allergic diseases: a randomized, double-blind, placebo-controlled trial. J Allergy Clin Immunol 2007, I 19:192-198.

38. Kalliomaki M, Salminen S, Poussa T, Isolauri E: Probiotics during the first 7 years of life: A cumulative risk reduction of eczema in a randomized, placebo-controlled trial. Journal of Allergy and Clinical Immunology 2007, II 9:1019-102I.

39. Lee J, Seto D, Bielory L: Meta-analysis of clinical trials of probiotics for prevention and treatment of pediatric atopic dermatitis. Journal of Allergy and Clinical Immunology 2008, 12 I: | 16- I2I.

40. Li Y, Ge Y, Saxena D, Caufield PW: Genetic profiling of the oral microbiota associated with severe early-childhood caries. J Clin Microbiol 2007, 45:8I-87.

4I. Andoh A, Sakata S, Koizumi Y, Mitsuyama K, Fujiyama Y, Benno Y: Terminal restriction fragment length polymorphism analysis of the diversity of fecal microbiota in patients with ulcerative colitis. Inflammatory Bowel Diseases 2007, I3:955-962.

42. Scanlan PD, Shanahan F, O'Mahony C, Marchesi JR: Culture-Independent Analyses of Temporal Variation of the Dominant
Fecal Microbiota and Targeted Bacterial Subgroups in Crohn's Disease. J Clin Microbiol 2006, 44:3980-3988.

43. Manichanh C, Rigottier-Gois L, Bonnaud E, Gloux K, Pelletier E, Frangeul L, Nalin R, Jarrin C, Chardon P, Marteau P, Roca J, Dore J: Reduced diversity of faecal microbiota in Crohn's disease revealed by a metagenomic approach. Gut 2006, 55:205-2II.

44. Sanz Y, Sanchez E, Marzotto M, Calabuig M, Torriani S, Dellaglio F: Differences in faecal bacterial communities in coeliac and healthy children as detected by PCR and denaturing gradient gel electrophoresis. FEMS Immunology \& Medical Microbiology 2007, $5 \mathrm{I}: 562-568$.

45. Collado MC, Calabuig M, Sanz Y: Differences between the fecal microbiota of coeliac infants and healthy controls. Curr Issues Intest Microbiol 2007, 8:9-I4.

46. Bergmann RL, Edenharter G, Bergmann KE, Forster J, Bauer CP, Wahn V, Zepp F, Wahn U: Atopic dermatitis in early infancy predicts allergic airway disease at 5 years. Clin Exp Allergy 1998, 28:965-70.

47. Burgess JA, Dharmage SC, Byrnes GB, Matheson MC, Gurrin LC, Wharton CL, Jonhs DP, Abramson MJ, Hopper JL, Walters EH: Childhood eczema and asthma incidence and persistence: a cohort study from childhood to middle age. J Allergy Clin Immunol 2008, I 22(2):280-5.
Publish with Bio Med Central and every scientist can read your work free of charge

"BioMed Central will be the most significant development for disseminating the results of biomedical research in our lifetime. "

Sir Paul Nurse, Cancer Research UK

Your research papers will be:

- available free of charge to the entire biomedical community

- peer reviewed and published immediately upon acceptance

- cited in PubMed and archived on PubMed Central

- yours - you keep the copyright 